\title{
Effects Of Saffron Supplementation On Inflammation And Metabolic Responses In Type 2 Diabetic Patients: A Randomized, Double-Blind, Placebo-Controlled
} Trial

\author{
Fatemeh Ebrahimi (D) ${ }^{1,2}$ \\ Amirhossein Sahebkar ${ }^{3-5}$ \\ Naheed Aryaeian (iD) ${ }^{2}$ \\ Naseh Pahlavani (iD ${ }^{6}$ \\ Soudabeh Fallah iD ${ }^{7}$ \\ Nariman Moradi ${ }^{8}$ \\ Davoud Abbasi iD ${ }^{9}$ \\ Agha Fatemeh Hosseini ${ }^{10}$
}

'Skull Base Research Center, Loghman Hakim Hospital, Shahid Beheshti University of Medical Sciences, Tehran, Iran;

${ }^{2}$ Department of Nutrition, School of Public Health, Iran University of Medical Sciences, Tehran, Iran; ${ }^{3} \mathrm{Halal}$ Research Center of IRI, FDA, Tehran, Iran; ${ }^{4}$ Biotechnology Research Center, Pharmaceutical Technology Institute, Mashhad University of Medical Sciences, Mashhad, Iran; ${ }^{5}$ Neurogenic Inflammation Research Center, Mashhad University of Medical Sciences, Mashhad, Iran; 'Student Research Committee, Mashhad University of Medical Sciences, Mashhad, Iran; ${ }^{7}$ Department of Clinical Biochemistry, Faculty of Medicine, Iran University of Medical Sciences, Tehran, Iran; ${ }^{8}$ Department of Clinical Biochemistry, Faculty of Medicine, Kurdistan University of Medical Sciences, Sanandaj, Iran;

${ }^{9}$ Department of Internal Medicine, Faculty of Medicine, Iran University of Medical Sciences, Tehran, Iran; ${ }^{10}$ Department of Biostatistics, School of Public Health, Iran University of Medical Sciences, Tehran, Iran

Correspondence: Naheed Aryaeian Department of Nutrition, School of Public Health, Iran University of Medical Sciences, Shahid Hemmat Expressway, Iran University of Medical Sciences, Hemat Highway next to Milad Towe Tehran, Tehran 14496/4535, Iran

Tel +98-9/2-3093353

Fax +98-2I-8862253

Email Aryaeian.n@iums.ac.ir
This article was published in the following Dove Press journal:

Diabetes, Metabolic Syndrome and Obesity: Targets and Therapy

Background: Type 2 diabetes (T2D) is accompanied by elevated inflammation, oxidative stress, hyperlipidemia and hyperglycemia which all contribute to cardiovascular disease pathogenesis. Saffron as a complementary medicine and source of antioxidants could play a role in alleviating diabetes and its complications. The aim of this study was to determine the effects of saffron supplementation as an adjunct therapy in T2D.

Patients and methods: This randomized controlled trial included 80 T2D patients with a mean age of 54.1 years. Participants were randomly assigned into two groups to take either saffron tablets $(100 \mathrm{mg} /$ day; $\mathrm{n}=40)$ or placebo $(\mathrm{n}=40)$ for 12 weeks. Fasting blood samples were obtained at the beginning and after the intervention period to quantify glycemic factors, lipid profile, and biomarkers of inflammation and oxidative stress. Anthropometric indices and dietary intakes were also measured at baseline and at study end.

Results: Compared with placebo, saffron supplementation resulted in significant decreases in waist circumference $(p<0.001)$ and malondialdehyde (MDA) $(p=0.001)$. There was no statistically significant difference in other indices, including anthropometric parameters, serum insulin, fasting blood glucose, $\mathrm{HbA1c}$, insulin sensitivity indices, lipid profile, high-sensitivity C-reactive protein, total antioxidant capacity, and tumor necrosis factor- $\alpha$ between the study groups $(p>0.05)$.

Conclusion: Overall, 12 weeks of saffron supplementation in diabetic patients had beneficial effects on waist circumference and serum MDA levels. However, saffron did not influence other evaluated cardio metabolic risk markers in diabetic patients.

Keywords: crocus sativus, diabetes mellitus, type 2, dysglycemia, lipid profile, inflammation mediators

\section{Introduction}

Type 2 diabetes (T2D) is characterized by three pathophysiological abnormalities, including impaired insulin secretion, insulin resistance, and excessive glucose production by the liver. ${ }^{1}$ T2D is currently one of the most common chronic diseases in the world, which is projected to reach over 650 million people worldwide in $2040{ }^{2}$ The prevalence of T2D in Iran is between $1.3 \%$ and $14.5 \%$, which increases with age. $^{3}$ The WHO estimates that diabetes is the most commonly reported endocrine disorder in the world, accounting for 4 million deaths annually worldwide. ${ }^{4}$

T2D is a major risk factor for cardiovascular disease (CVD) and a risk equivalent for coronary artery disease. ${ }^{5}$ Impaired insulin secretion as well as hyperglycemia is a causal 
risk factor for macrovascular complications in diabetic and non-diabetic persons. ${ }^{6,7}$ Although the relationship between insulin resistance and vascular diseases has been shown, an exact mechanism for the association between T2D and atherosclerosis has not yet been proven. ${ }^{8}$ Chronic inflammation is an accompanying feature of $\mathrm{T} 2 \mathrm{D}$ that is associated with disease progression and complications. ${ }^{9,10}$ The metabolic syndrome that is characterized by increased waist circumference, insulin resistance, hyperglycemia, dyslipidemia, and hypertension is associated with an increased risk of developing T2D and CVD. ${ }^{11}$ The control of metabolic syndrome and cardiovascular risk factors can decrease the risk morbidity and mortality of T2D. ${ }^{12,13}$

Treatment options for T2D include lifestyle modification through improving diet and physical activity. ${ }^{13,14}$ Although there are many drug classes to improve glycemic control of diabetes, they have limited efficacy in preventing events and diabetic complications. ${ }^{14}$ Therefore, using complementary and alternative treatments, particularly botanicals, has been suggested to improve glycemic control and CVD risk in T2D patients. ${ }^{14,15}$ Saffron, a spice derived from the stigmas of Crocus sativus L., has a distinctive smell, taste, and color that makes it a widely used flavoring agent in cosmetic and food preparation. ${ }^{16}$ Saffron contains more than 100 active ingredients such as crocin, crocetin, and safranal, and has been shown to possess anti-depressant, neuroprotective, anti-tumor, anticonvulsant, anti-hypertensive, anti-ischemic, hypolipidemic, antioxidant, and anti-inflammatory effects. ${ }^{17,18}$ In previous studies, the positive effects of saffron, either alone or in combination with other herbal medicines, have been shown on the risk factors of $\mathrm{T}_{2} \mathrm{D}^{19,20}$ but these results are inconsistent and subject to heterogeneity due to different doses of saffron and different durations of supplementation.

The present study was therefore performed to examine the effects of saffron supplementation on anthropometric, glycemic, lipid profile, inflammatory, and oxidative indices in $\mathrm{T} 2 \mathrm{D}$ patients.

\section{Materials And Methods}

\section{Participants}

During the period between December 2015 and October 2017, 90 patients aged 30-70 years referred to the Iranian Diabetes Society and Institute of Endocrinology and Metabolism, Firouzgar Hospital, and fulfilled the inclusion criteria. The studied patients were diagnosed with T2D by an endocrinologist on the basis of the findings of the hematological tests and have the criteria for our examination. These criteria included disease duration for at least 3 years, HbA1c level of $6.5-10 \%$, taking no nutritional supplements for at least 3 months prior to the intervention, no smoking, and alcohol abuse during the last year and body mass index (BMI) between 20 and $35 \mathrm{~kg} / \mathrm{m}^{2}$. The exclusion criteria were as follows: insulin therapy at baseline or amid the examination, changes in the type or dose of drug treatment, changes in lifestyle such as physical activity and food intake, any acute diseases or chronic illnesses, smoking, pregnancy and lactation, consumption of saffron or other herbal supplements, saffron hypersensitivity, and taking of less than $80 \%$ of the intervention amid the investigation time frame.

\section{Study Design}

We conducted a prospective, double-blind, placebo-controlled, randomized study that was registered in the Iranian Registry of Clinical Trials (IRCT, www.irct.ir) under registration no: IRCT201510259472N9. The study was approved by the Ethics Committee of the Iran University of Medical Sciences, Tehran, Iran (registration no: IR.IUMS.REC.1394.26583), and a written informed consent was obtained from all subjects.

To estimate the required population size, we used a formula suggested for randomized trials $\left(\mathrm{n}=\frac{2(\mathrm{Zl}+\mathrm{Z} 2) \sigma^{2}}{d^{2}}\right) .^{21}$ The required number of subjects in each group was 45 , considering a power of $80 \%$, type I error of $5 \%(\alpha=0.05)$ and type II error of $20 \%(\beta=0.20)$. Totally, 90 individuals were selected at baseline, and were followed for 12 weeks. Subjects were randomly allocated to the saffron supplement group $(n=45)$ or placebo group $(\mathrm{n}=45)$. The randomization scheme was generated using a computer-based random number generator.

\section{Measurement}

Detailed information about age, weight, height, gender, and medications were collected. Participant weights with light apparel yet without shoes were estimated through an offset with $100 \mathrm{~g}$ precision; height, in standing position and without shoes was estimated through a tallness measurer with $0.5 \mathrm{~cm}$ exactness both toward the start and the 12 weeks of the study. At the start and termination of the intervention, levels of physical activity were specified by IPAQ (International Physical Activity Questionnaire), which its reliability and validity in Iran are accomplished. ${ }^{22,23}$ This survey evaluates strolling time, moderate and lively power physical exercises, and time spent sitting over a typical 
week. This regular physical activity continued within the intervention and participants were asked not to change their physical activity during the intervention. However, the differences between the two classes of the intervention were adjusted in the last analysis.

All individuals were permitted to taking their routine drug treatment according to their physician's prescription. We are taking dietary records (3 days) at the beginning (day 1), middle (day 42), and end (day 84) of the intervention. The mean qualities from each of the three-time focuses were considered as regular dietary intake of patients amid the study. Participants were asked to register all things they are taking during the day, including the between-meal, supplement, and late-evening snacks as accurately as possible. All food records at home were completed by participants. ${ }^{24}$

To acquire nutrient taking of the individuals based on these 3-day dietary records, we used Nutritionist IV software (based on US National Nutrient Databank) modified for Iranian foods that the reliability and validity have been accomplished previously. ${ }^{25}$

Ten milliliters of fasting blood samples were collected in 10-12 hrs fasting state at the starting and 12th week after the intervention at the Tehran laboratory. The serum was obtained by high-speed centrifugation $(3000 \mathrm{rpm})$ at $4^{\circ} \mathrm{C}$ for 10 mins and was frozen immediately at $-80^{\circ} \mathrm{C}$ until assay.

The concentration of insulin was determined by the immunoenzymometric assay (ELISA) kits (Monobind Inc., Lake Forest, CA, USA). Homeostatic Model Assessment for Insulin Resistance (HOMA-IR) and Quantitative Insulin Sensitivity Check Index (QUICKI) were quantified based on recommended formulae: [fasting insulin $(\mathrm{mU} / \mathrm{mL}) \times$ fasting glucose $(\mathrm{mg} / \mathrm{dL})] / 405$ and $1 /(\log$ (fasting insulin $\mathrm{mU} / \mathrm{mL}$ ) $+\log$ (fasting glucose $\mathrm{mg} / \mathrm{dL}$ ), respectively. Total antioxidant capacity (TAC) was determined using a Randox Total Antioxidant Status kit (Randox Laboratories, Northern Ireland). ${ }^{26} \mathrm{HbA1c}$ level was determined using ion-exchange chromatography. Enzymatic kits (Pars Azmun) were used to quantify FBS, serum TG, total cholesterol, low-density lipoprotein-cholesterol (LDL-C), and low-density lipoprotein-cholesterol (HDL-C) concentrations. Quantification of serum high-sensitivity C-reactive protein (hs-CRP) levels were measured by biochemical analysis using the immunoturbidimetry assay via a Biosystem CPR-hs kit (Biosystem, SA, Barcelona, Spain). The malondialdehyde (MDA) activity in serum (used as a marker for oxidative stress) was measured through a reaction with thiobarbituric acid, a highly sensitive method in order to produce a pink-colored complex. The fluorescent intensity of the pink-colored complex was determined at $547 \mathrm{~nm}$ with an excitation at $525 \mathrm{~nm}$ using a spectrofluorometer (model SFM 25A; Kontron, Milan, Italy). ${ }^{27}$

\section{Intervention}

After divided of participants to intervention and control groups, patients in the saffron group received daily a tablet containing $100 \mathrm{mg}$ saffron (Novin Saffron Co., Mashhad, Iran), twice a day (at the morning $(10 \mathrm{am})$ and evening $(6 \mathrm{pm})$ with a glass of water and without meals) and those in the control group received daily the same amount of placebo (maltodextrin) for 12 weeks. The manifest of the placebo tablets (including color and bundling) was like to the saffron tablets. All participants were asked not to change their regular diet and intake of food during the study, as well as not to take any supplement except saffron pills.

\section{Statistical Analysis}

All data analyzed by means of SPSS software version 18 (SPSS, Inc., Chicago, IL, USA). We used the Kolmogorov-Smirnov test to determine the normal distribution of variables. Log transformation was conducted for non-normally distributed variables. Independent-samples $t$-test was used for homogeneity of the data. To compare the differences between saffron and placebo groups, we used independent-samples $t$-test (Mann-Whitney $U$-test in non-parametric distribution). We used Chi-squared test for physical activity analyses. To find if the magnitude of the change depended on primary values, physical activity, and usual food taking, we adjusted these variables by applying analysis of covariance to acquire the independent effect of saffron supplementation on anthropometric, inflammatory and oxidative stress indices, lipid profile, and glycemic indices. $p$-Value $<0.05$ was considered as significant level. All values have been reported as mean $\pm \mathrm{SD}$.

\section{Results}

Initially, 90 patients with T2D were screened. In the current study, 5 subjects in the intervention group and 5 in the control group dropped out for private reasons, need to insulin, migration and stomach problems, and 80 patients were analyzed (Figure 1). In this trial, 100\% of the assigned powders were consumed in two groups and the rate of compliance in current study was high. Baseline demographic data including gender, age, weight, height, BMI, waist circumference, duration of $\mathrm{T} 2 \mathrm{D}$, and types of 


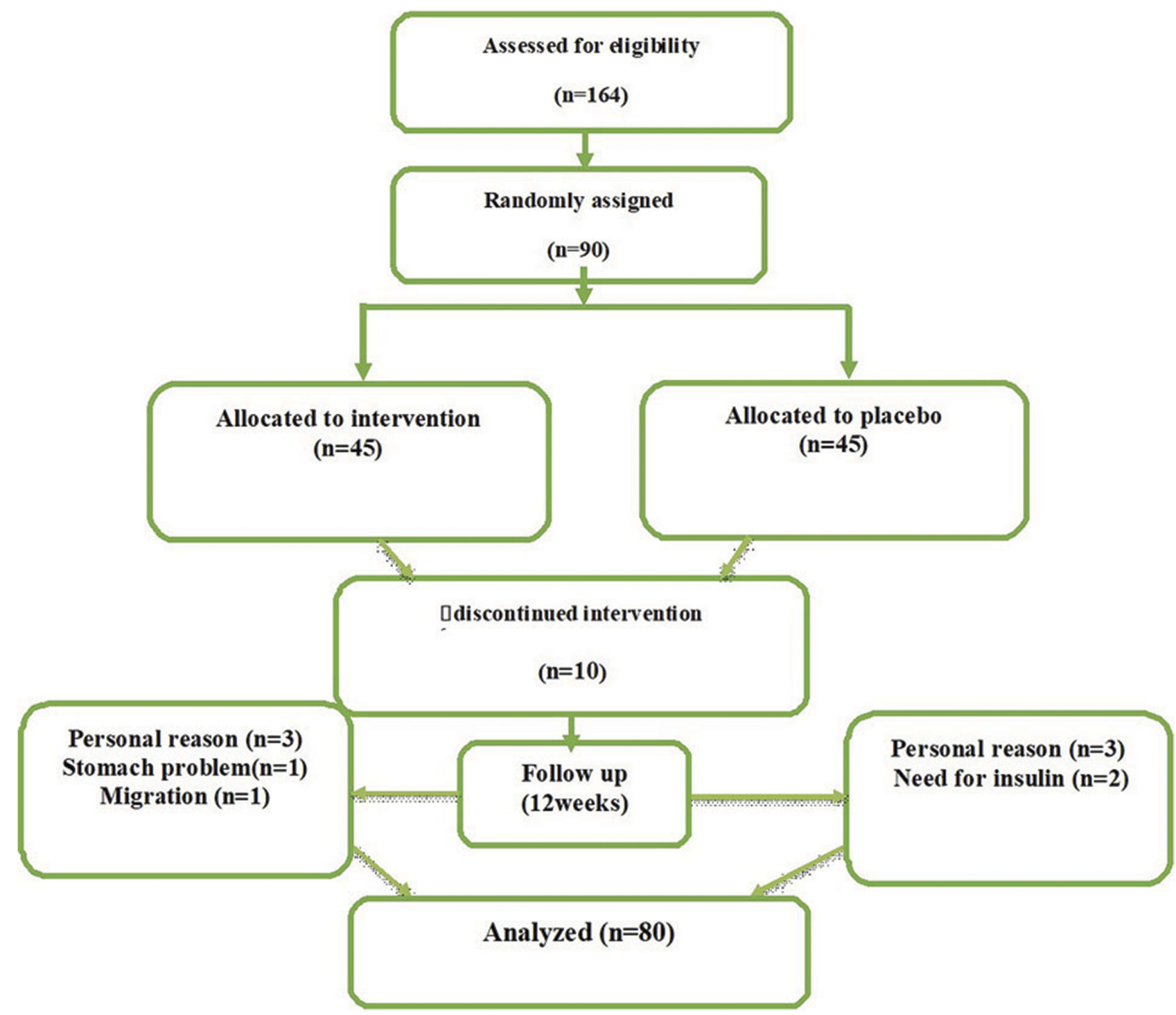

Figure I Schematic diagram of the study design; individuals in the intervention group received a tablet containing $100 \mathrm{mg}$ of saffron per day during the study and those in the placebo group received $100 \mathrm{mg}$ maltodextrin tablet at the same time.

hypoglycemic drugs in randomized patients are shown in Table 1 . There was no difference in the parameters between the saffron and placebo groups at baseline $(p>0.05)$.

Based on 3-day dietary records that acquired at study beginning and throughout the study, we observed no significant differences in macronutrients (energy, carbohydrate, protein, and fat) and micronutrient intakes (vitamins A, E, C, zinc, selenium, and beta-carotene) between the 2 groups (Table 2). Moreover, physical activity level was not different before and after the study (Table 3).

Compared with the control, saffron supplementation resulted in a significant reduction in waist circumference and this result remained significant after adjusting for covariates $(p<0.001)$ but other anthropometric indices such as BMI, body fat percentage, and weight did not show a significant changes between the two (saffron and control) groups, though weight, waist circumference, and BMI were reduced in the saffron group compared with their baseline values $(p<0.001$, Table 4$)$. There was no significant difference between the study group in terms of glycemic and lipid indices including FBS, $\mathrm{HbA1c}$, serum insulin, HOMA-IR, QUICKI, triglycerides, LDL-C, and HDL-C, despite a significant reduction in HbAlc and elevation of total cholesterol in the saffron group (Table 5).

Although hs-CRP ( $p=0.016)$, TAC ( $p=0.03)$, and MDA $(p<0.001)$ were significantly decreased in the saffron group compared with baseline, these changes did not 
Table I General Baseline Characteristics Of Subjects Who Received Either Saffron Or Placebo

\begin{tabular}{|c|c|c|c|c|}
\hline \multicolumn{2}{|l|}{ Variables } & $\begin{array}{l}\text { Saffron } \\
\text { Group }^{a}\end{array}$ & $\begin{array}{l}\text { Placebo } \\
\text { Group }^{b}\end{array}$ & p Value \\
\hline \multicolumn{2}{|l|}{ Age (years) } & $55.2 \pm 7.3$ & $53 \pm 10.6$ & 0.61 \\
\hline Sex & $\begin{array}{l}\text { Male } \mathrm{n}(\%) \\
\text { Female } \mathrm{n}(\%)\end{array}$ & $\begin{array}{l}20(50) \\
20(50)\end{array}$ & $\begin{array}{l}1638 \\
24(60)\end{array}$ & 0.51 \\
\hline \multicolumn{2}{|l|}{$\begin{array}{l}\text { Height (cm) } \\
\text { Weight (kg) } \\
\text { BMI }\left(\mathbf{k g} / \mathbf{m}^{2}\right) \\
\text { WC }(\mathrm{cm})\end{array}$} & $\begin{array}{l}162 \pm 9.9 \\
75.3 \pm 12.8 \\
29.3 \pm 4.9 \\
106 \pm 9.5\end{array}$ & $\begin{array}{l}163.7 \pm 8.3 \\
80.3 \pm 12.8 \\
30.5 \pm 4.7 \\
107.8 \pm 12.9\end{array}$ & $\begin{array}{l}0.41 \\
0.08 \\
0.25 \\
0.75\end{array}$ \\
\hline \multicolumn{2}{|c|}{$\begin{array}{l}\text { Duration of type } 2 \text { diabetes } \\
\text { (year) }\end{array}$} & $7.8 \pm 5.4$ & $6.6 \pm 6.1$ & 0.13 \\
\hline $\begin{array}{l}\text { Types of } \\
\text { hypoglycemic } \\
\text { drugs }\end{array}$ & $\begin{array}{l}\text { Metformin n (\%) } \\
\text { Metformin } \\
\text { +glibenclamide } \\
\mathrm{n}(\%) \\
\text { Metformin } \\
\text { +glibenclamide } \\
\text { +zeptin n (\%) } \\
\text { Other drugs } \\
\mathrm{n}(\%)\end{array}$ & $\begin{array}{l}4(10) \\
8(20) \\
10(25) \\
18(45)\end{array}$ & $\begin{array}{l}6(15) \\
13(32.5) \\
8(20) \\
13(32.5)\end{array}$ & 0.454 \\
\hline
\end{tabular}

Notes: All quantitative values are means $\pm S D$ s. All qualitative values are expressed

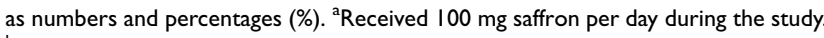
${ }^{\mathrm{b}}$ Received $100 \mathrm{mg}$ placebo per day during the study. 'Obtained from independentsamples $t$-test for quantitative values and Chi-square for qualitative values.

Abbreviations: BMI, body mass index; WC, waist circumference.

Table 2 Usual Dietary Intake Of Participants During The Study Who Received Either Saffron Or Placebo During The Study

\begin{tabular}{|l|l|l|l|}
\hline Variables & $\begin{array}{l}\text { Saffron } \\
\text { Group }^{\mathbf{a}}\end{array}$ & $\begin{array}{l}\text { Placebo } \\
\text { Group }^{\mathbf{b}}\end{array}$ & $p$ Value \\
\hline Energy Intake (kcal) & $1848 \pm 164$ & $1890 \pm 160$ & 0.608 \\
Carbohydrate (g per day) & $230.6 \pm 38.8$ & $279.4 \pm 277.7$ & 0.275 \\
Protein intake (g per day) & $59.4 \pm 12.5$ & $80.2 \pm 158.5$ & 0.411 \\
Fat (g per day) & $83.2 \pm 14.2$ & $84.2 \pm 17.2$ & 0.799 \\
Vitamin A (retinol equivalent) & $465 \pm 327.4$ & $465 \pm 612.9$ & 0.105 \\
Vitamin E (mg per day) & $32.7 \pm 45.5$ & $24.4 \pm 5.8$ & 0.255 \\
Vitamin C (mg per day) & $64.3 \pm 43.5$ & $68.9 \pm 40.8$ & 0.626 \\
Zinc (mg per day) & $12.5 \pm 33.2$ & $7.8 \pm 1.3$ & 0.364 \\
Selenium (mg per day) & $0.055 \pm 0.02$ & $0.02 \pm 0.02$ & 0.589 \\
Beta-carotene (mg per day) & $587 \pm 449$ & $743 \pm 770$ & 0.272 \\
\hline
\end{tabular}

Notes: All values are mean $\pm S D$. ${ }^{2}$ Received $100 \mathrm{mg}$ saffron per day during the study. ${ }^{\mathrm{b}}$ Received $100 \mathrm{mg}$ placebo per day during the study. 'Obtained from independentsamples $t$-test.

reach statistical significance compared to placebo. In contrast, MDA showed a significant decrease in the saffron compared with the placebo group $(p=0.001)$. No significant alteration in serum tumor necrosis factor- $\alpha$ (TNF- $\alpha$ ) levels was observed in either of the studied groups ( $p=0.796$, Table 6).

\section{Discussion}

Prevalence of T2D and its associated comorbidities necessitate the use of adjunct therapies. ${ }^{28}$ Saffron was used in this study owing to its diverse reported effects on glycemic and cardiovascular indices. ${ }^{29}$

In this study, we examined the effects of 12 weeks of saffron supplementation on anthropometric and glycemic indices, lipid profile and inflammatory and oxidative stress biomarkers among T2D patients. We showed that saffron intake for 12 weeks among these participants had useful effects on waist circumference and MDA, however it did not influence glycemic indices, hs-CRP, lipid profile, TNF- $\alpha$, and TAC levels compared with the control group.

In the present study, the use of $100 \mathrm{mg}$ /day saffron tablets reduced waist circumference between intervention group in comparison with and control groups and also significantly reduced body weight and BMI within the saffron group. However, Azimi et al's study reported that after drinking 3 daily glasses of saffron tea (containing $1 \mathrm{~g}$ saffron) for 8 weeks no significant effect was seen on weight, BMI, and waist circumferences among T2D patients. ${ }^{19}$ This discrepancy in findings might be because of the intake of tea instead of pure saffron. In agreement with our study, in one study that was conducted by Ahmadi Khatir et al, supplementation with $100 \mathrm{mg}$ /day saffron for 6 weeks in patients with atherosclerosis decreased waist circumference and hip circumference but did not affect other anthropometric indices, such as weight and BMI. They also showed that saffron had no significant effect on FBS, total cholesterol, triglycerides, HDL-C, and LDL-C. ${ }^{30}$ We did not observe significant changes in lipid profile parameters such as triglycerides, total cholesterol, LDL-C and HDL-C concentrations, and glycemic indices throughout the intervention; however, in another study supplementation with $1 \mathrm{~g}$ /day saffron with other herbal medicine such as cinnamon, cardamom, and ginger in type T2D patients for 8 weeks significantly decreased total cholesterol and LDL-C, and increased HDL-C levels compared with control but the combination herbal product did not have any significant effect on FBS, HbA1c, and hsCRP. ${ }^{19}$ The significant effects on lipid profiles are probably due to the combination of several types of herbal medicine and their synergistic effects with the mechanisms of increased activity of antioxidant enzymes and the improvement of insulin sensitivity. ${ }^{31,32}$ In Milajerdi et al's study, saffron extract intake with dose $30 \mathrm{mg} /$ day for 8 weeks among T2D patients could significantly 
Table 3 Physical Activity Measurements At The Study Baseline And 12 Weeks After Intervention In Two Groups

\begin{tabular}{|c|c|c|c|c|c|c|c|}
\hline Group & \multicolumn{3}{|c|}{ Intervention Group (Saffron) } & \multicolumn{3}{|c|}{ Control Group (Maltodextrin) } & \multirow[t]{2}{*}{$p$ Value $^{\mathrm{b}}$} \\
\hline Intervention & Low & Moderate & Severe & Low & Moderate & Severe & \\
\hline $\begin{array}{l}\text { Before intervention } \\
n \\
(\%)\end{array}$ & $\begin{array}{l}24 \\
(60)\end{array}$ & $\begin{array}{l}12 \\
(30)\end{array}$ & $\begin{array}{l}4 \\
(10)\end{array}$ & $\begin{array}{l}32 \\
(80)\end{array}$ & $\begin{array}{l}5 \\
(12.5)\end{array}$ & $\begin{array}{l}3 \\
(7.5)\end{array}$ & 0.124 \\
\hline $\begin{array}{l}\text { After intervention } \\
\mathrm{n} \\
\text { (\%) }\end{array}$ & $\begin{array}{l}24 \\
(60)\end{array}$ & $\begin{array}{l}12 \\
(30)\end{array}$ & $\begin{array}{l}4 \\
(10)\end{array}$ & $\begin{array}{l}32 \\
(80)\end{array}$ & $\begin{array}{l}5 \\
(12.5)\end{array}$ & $\begin{array}{l}3 \\
(7.5)\end{array}$ & 0.124 \\
\hline
\end{tabular}

Notes: aPhysical activity, bobtained from Chi-squared test.

Table 4 Anthropometric Indices Measurement At Study Baseline And 12 Weeks After The Intervention In Subjects Who Received Either Saffron Or Placebo

\begin{tabular}{|c|c|c|c|c|c|c|c|}
\hline \multirow[t]{2}{*}{ Variables } & \multicolumn{2}{|c|}{ Saffron Group ${ }^{a}$} & \multirow[t]{2}{*}{ P-value ${ }^{\text {b }}$} & \multicolumn{2}{|c|}{ Placebo Group ${ }^{c}$} & \multirow[t]{2}{*}{ P-value ${ }^{\text {b }}$} & \multirow[t]{2}{*}{ P-value ${ }^{d}$} \\
\hline & Baseline & After & & Baseline & After & & \\
\hline Body weight (kg) & $75.38 \pm 12.78$ & $74.15 \pm 12.94$ & $<0.001$ & $80.32 \pm 12.87$ & $78.79 \pm 18.14$ & 0.469 & 0.882 \\
\hline BMI $\left(\mathrm{kg} / \mathrm{m}^{2}\right)$ & $28.7 \pm 4.15$ & $28.21 \pm 4.07$ & $<0.001$ & $29.91 \pm 3.91$ & $29.27 \pm 6.57$ & 0.449 & $0.86 \mathrm{I}$ \\
\hline$W C(\mathrm{~cm})$ & $104.31 \pm 7.85$ & $100.02 \pm 7.32$ & $<0.001$ & $102.95 \pm 7.94$ & $104.33 \pm 7.42$ & 0.048 & $<0.001$ \\
\hline Body fat (\%) & $35.42 \pm 6.60$ & $34.74 \pm 7.66$ & 0.421 & $36.89 \pm 6.77$ & $44.26 \pm 45.83$ & 0.317 & 0.882 \\
\hline
\end{tabular}

Notes: ${ }^{a}$ Received $100 \mathrm{mg}$ saffron per day during study. ${ }^{\mathrm{b}}$ Obtained from paired-samples $t$-test. ${ }^{\mathrm{C}}$ Received $100 \mathrm{mg}$ placebo per day during the study. ${ }^{\mathrm{d}} \mathrm{Obtained}$ from independent-samples $t$-test.

Abbreviations: BMI, body mass index; WC, waist circumference.

Table 5 Glycemic Indices And Lipid Profiles Measurement At Study Baseline And 12 Weeks After The Intervention In Subjects Who Received Either Saffron Or Placebo

\begin{tabular}{|c|c|c|c|c|c|c|c|}
\hline \multirow[t]{2}{*}{ Variables } & \multicolumn{2}{|c|}{ Saffron Group ${ }^{a}$} & \multirow[t]{2}{*}{ P-value ${ }^{b}$} & \multicolumn{2}{|c|}{ Placebo Group ${ }^{c}$} & \multirow[t]{2}{*}{ P-value ${ }^{b}$} & \multirow[t]{2}{*}{ P-value $^{d}$} \\
\hline & Baseline & After & & Baseline & After & & \\
\hline FBS (mg/dL) & $166.7 \pm 53.7$ & $162.1 \pm 52.7$ & 0.633 & $160.9 \pm 51.1$ & $|47.7 \pm 5| .8$ & 0.134 & 0.504 \\
\hline $\mathrm{HbAlc}(\%)$ & $8.01 \pm 1.40$ & $7.69 \pm 1.49$ & 0.047 & $7.38 \pm 1.53$ & $7.34 \pm 1.48$ & 0.831 & 0.209 \\
\hline Serum insulin(pico Mol/L) & $4.70 \pm 1.7$ & $4.70 \pm 1.9$ & 0.972 & $4.47 \pm 1.8$ & $4.7 I \pm 2.05$ & 0.206 & 0.404 \\
\hline HOMA-IR & $1.91 \pm 0.95$ & $1.89 \pm 1.03$ & 0.89 & $1.79 \pm 0.93$ & $1.80 \pm 1.22$ & 0.94 & 0.88 \\
\hline QUICKI & $0.153 \pm 0.009$ & $0.154 \pm 0.011$ & 0.47 & $0.156 \pm 0.014$ & $0.157 \pm 0.016$ & 0.34 & 0.86 \\
\hline Triglyceride (mg/dL) & $165.8 \pm|2| .8$ & $175 \pm 98 . \mid$ & $0.267^{e}$ & $170.4 \pm 63.5$ & $168 \pm 58.3$ & $0.692^{\mathrm{e}}$ & $0.30^{f}$ \\
\hline Total cholesterol (mg/dL) & $143.7 \pm 36.6$ & $|52.8 \pm 3| .4$ & 0.029 & $147 \pm 32.5$ & $155.1 \pm 37.2$ & 0.068 & 0.86 \\
\hline LDL-C (mg/dL) & $82.7 \pm 25.7$ & $89.5 \pm 23.9$ & 0.069 & $84.5 \pm 26.6$ & $90.7 \pm 30.5$ & 0.081 & 0.90 \\
\hline HDL-C (mg/dL) & $41.8 \pm 8.4$ & $42.2 \pm 9.4$ & 0.732 & $44.35 \pm 10.1$ & $44.9 \pm 11.3$ & 0.676 & 0.91 \\
\hline
\end{tabular}

Notes: ${ }^{a}$ Received $100 \mathrm{mg}$ saffron per day during the study. ${ }^{\mathrm{b}}$ Obtained from paired-samples $t$-test. ${ }^{\mathrm{c}}$ Received $100 \mathrm{mg}$ placebo per day during the study. ${ }^{\mathrm{d}}$ Obtained from independent-samples $t$-test. ${ }^{~}$ Obtained from Wilcoxon signed-rank test. ${ }^{f}$ Obtained from Mann-Whitney U-test.

Abbreviations: FBS, fasting blood sugar; HbAIc, glycosylated hemoglobin; HOMA-IR, Homeostatic Model Assessment for Insulin Resistance; QUICKI, Quantitative Insulin Sensitivity Check Index; LDL-C, low-density lipoprotein-cholesterol; HDL-C, high-density lipoprotein-cholesterol.

decrease FBS; however, these effects were not significant on lipid profile and HbAlc. ${ }^{20}$ In another study, saffron supplementation with a dose of $30 \mathrm{mg} /$ day for 4 weeks did not have a significant effect on lipid profiles in patients with major depression. ${ }^{33}$
Oxidative stress is the cause of numerous chronic diseases, resulting in an imbalance between the production of free radicals, and the inability of the antioxidant systems in the body to neutralize these free radicals. ${ }^{34}$ In an experimental study, crocin as the main ingredient of saffron 
Table 6 Inflammatory Indices, Malondialdehyde And Total Antioxidant Capacity Measurement At Study Baseline And I2 Weeks After The Intervention In Subjects Who Received Either Saffron Or Placebo

\begin{tabular}{|c|c|c|c|c|c|c|c|}
\hline \multirow[t]{2}{*}{ Variables } & \multicolumn{2}{|c|}{ Saffron Group ${ }^{a}$} & \multirow[t]{2}{*}{$P$-value ${ }^{b}$} & \multicolumn{2}{|c|}{ Placebo Groupc } & \multirow[t]{2}{*}{ P-value ${ }^{b}$} & \multirow[t]{2}{*}{$P$-value } \\
\hline & Baseline & After & & Baseline & After & & \\
\hline TNF- $\alpha$ (mg/dL) & $19.1 \pm 8.1$ & $18.3 \pm 7.8$ & 0.147 & $18.3 \pm 7.9$ & $17.3 \pm 6.5$ & 0.076 & 0.796 \\
\hline hs-CRP (mg/dL) & $2.7 \pm 1.1$ & $2.5 \pm 1$ & 0.016 & $2.5 \pm 0.9$ & $2.4 \pm 0.8$ & 0.557 & 0.124 \\
\hline MDA $(\mu \mathrm{M} / \mathrm{L})$ & $17.8 \pm 0.17$ & $16.7 \pm 3.5$ & $<0.001$ & $15.8 \pm 2.7$ & $15.9 \pm 2.7$ & 0.760 & 0.001 \\
\hline TAC $(\mu \mathrm{M} / \mathrm{L})$ & $2.04 \pm 0.7$ & $1.98 \pm 0.6$ & 0.03 & $2.1 I \pm 0.6$ & $2.1 \pm 0.6$ & 0.273 & 0.230 \\
\hline
\end{tabular}


independent-samples $t$-test.

Abbreviations: TNF- $\alpha$, tumor necrosis factor-alpha; hs-CRP, high-sensitivity C-reactive protein; MDA, malondialdehyde; TAC, total antioxidant capacity.

could improve insulin resistance and lipid profile in diabetic rats. ${ }^{35}$ In another animal study, crocin was shown to improve inflammatory factors, glycemic indices, and obesity in diabetic rats. ${ }^{36}$ While crocin appears to improve cardiometabolic risk factors, its content in the crude saffron may be lower than that required to elicit a pharmacological response. At the end of our study, except MDA there were no significant changes between two groups regarding TNF- $\alpha$, TAC, and hs-CRP reduction. Saffron intake caused a significant reduction in TAC and hs-CRP levels in within-group comparisons. Saffron contains some components such as anthocyanin, flavonoids, saponins, alkaloids, and tannins which may have contributed to its anti-inflammatory effects. ${ }^{37}$ In the previous in vitro study crocetin derived from saffron has been able to reduce levels of MDA, free radicals, and increased the elimination of free radicals. ${ }^{38}$

The exact mechanism explaining the effect of saffron on anthropometric and glycemic indices, lipid profile, and oxidative and inflammatory biomarkers is unknown. However, the probably mechanisms that saffron may be able to improve the inflammatory and oxidative stress markers include increasing the levels of glutathione reductase, and scavenging free radicals. ${ }^{39}$ In addition, saffron has antioxidant and anti-inflammatory properties and may improve micro-vascular and macro-vascular complications of T2D. ${ }^{40,41}$ In a systematic review and meta-analysis, it was shown that saffron and its constituents have significant effects on body weight, waist circumference, and diastolic blood pressure, but there was no significant effect on BMI, systolic blood pressure, HbA1C, lipid profiles, and fasting insulin levels. ${ }^{42}$ The contrasting findings may be due to different doses used, different content of crocin in the administered supplements and different baseline properties as well as durations of follow-up. ${ }^{42}$
The current study had some limitations. We did not determine the effects of saffron consumption on other biomarkers of oxidative stress and inflammation, such as superoxide dismutase, reactive oxygen and nitrogen species, matrix metalloproteinase, and other biomarkers. In addition, we could not measure the metabolites of saffron inside the body. Due to the fact that the given dose of saffron in the present study (tablets containing of $100 \mathrm{mg} /$ day saffron) did not lead to any clinical complications, it is suggested in future studies to use higher doses of the saffron. Moreover, given the anti-diabetic activity of saffron ingredients such as crocin, future investigations are required to test if individual saffron components can improve T2D risk factors. Some of the main strengths of our study were the assessment of markers of glucose metabolism and its randomized design. In addition, differences between the two groups were minimized because the subject population was well defined by the inclusion and exclusion criteria and all individuals selected from the same health center and having exact data on diet and physical activity.

In conclusion, this randomized double-blind controlled clinical trial demonstrated that saffron $(100 \mathrm{mg} /$ day $)$ intake for 12 weeks in type 2 patients had beneficial effects on waist circumference and MD levels; however, it did not influence glycemic, lipid, and inflammatory indices in comparison with the placebo group.

\section{Abbreviations}

T2D, type 2 diabetes; MDA, malondialdehyde; FBG, fasting blood glucose; HbAlc, glycated hemoglobin A; hs-CRP, highsensitivity C-reactive protein; TAC, total antioxidant capacity; TNF-a, tumor necrosis factor- $\alpha$; WC, waist circumference; CVD, cardiovascular disease; NIDDM, non-insulin dependent diabetes mellitus; BMI, body mass index; IPAQ, The International Physical Activity Questionnaire; TC, total 
cholesterol; TG, triglyceride; LDL, low-density lipoprotein; HDL, high-density lipoprotein; ANCOVA, analysis of covariance; TBA, thiobarbituric acid; TAS, total antioxidant status; HOMA-IR, Homeostatic Model Assessment for Insulin Resistance; QUICKI, Quantitative Insulin Sensitivity Check Index.

\section{Compliance With Ethical Standards}

This paper was adapted from MSc dissertation and done according to the guidelines of the Helsinki Declaration and all procedures involving human patients were approved by the Ethics Committee of Iran University of Medical Sciences (code: IR.IUMS.REC.1394.26583) and supported by the Department of Nutrition, School of Public Health of this University. Written informed consent was obtained from all patients before starting the study.

\section{Data Sharing Statement}

Patients' private information in our study is not publicly available because of lack of agreement for disclosing individual data in public but are available from the corresponding and first author on reasonable requests and can be uploaded to the journal site as raw data whenever requested.

\section{Acknowledgments}

The authors wish to thank all the participants, Iranian Diabetes Society and Institute of Endocrinology and Metabolism, Firouzgar Hospital, Iran University of Medical Sciences, Tehran, Iran for their financial support in performing this trial.

\section{Disclosure}

The authors report no conflicts of interest in this work.

\section{References}

1. Kahn SE, Cooper ME, Del Prato S. Pathophysiology and treatment of type 2 diabetes: perspectives on the past, present, and future. Lancet. 2014;383(9922):1068-1083. doi:10.1016/S0140-6736(13)62154-6

2. Guariguata L, Nolan T, Beagley J; International diabetes federation. IDF Diabetes Atlas. Brussels: International Diabetes Federation; 2014.

3. Azimi-Nezhad M, Ghayour-Mobarhan M, Parizadeh MR, et al. Prevalence of type 2 diabetes mellitus in Iran and its relationship with gender, urbanisation, education, marital status and occupation. Singapore Med J. 2008;49(7):571-576. PubMed PMID: 18695867. Epub 2008/ 08/13.eng.

4. Shah A, Mehta N, Reilly MP. Adipose inflammation, insulin resistance, and cardiovascular disease. JPEN J Parenter Enteral Nutr. 2008;32(6):638-644. doi:10.1177/0148607108325251

5. Gu K, Cowie CC, Harris MI. Diabetes and decline in heart disease mortality in US adults. JAMA. 1999;281(14):1291-1297. doi:10.10 01/jama.281.14.1291
6. Varughese G, Tomson J, Lip G. Type 2 diabetes mellitus: a cardiovascular perspective. Int $J$ Clin Pract. 2005;59(7):798-816. doi:10.1111/j.1368-5031.2005.00571.x

7. Kragelund C, Snorgaard O, Køber L, et al. Hyperinsulinaemia is associated with increased long-term mortality following acute myocardial infarction in non-diabetic patients. Eur Heart J. 2004;25 (21):1891-1897. doi:10.1016/j.ehj.2004.07.033

8. Mazloom Z, Yousefinejad A, Dabbaghmanesh MH. Effect of probiotics on lipid profile, glycemic control, insulin action, oxidative stress, and inflammatory markers in patients with type 2 diabetes: a clinical trial. Iran J Med Sci. 2013;38(1):38.

9. Vozarova B, Weyer C, Lindsay RS, Pratley RE, Bogardus C, Tataranni PA. High white blood cell count is associated with a worsening of insulin sensitivity and predicts the development of type 2 diabetes. Diabetes. 2002;51(2):455-461. doi:10.2337/diabetes.51.2.455

10. Duncan BB, Schmidt MI, Pankow JS, et al. Low-grade systemic inflammation and the development of type 2 diabetes: the atherosclerosis risk in communities study. Diabetes. 2003;52(7):17991805. doi:10.2337/diabetes.52.7.1799

11. Esser N, Legrand-Poels S, Piette J, Scheen AJ, Paquot N. Inflammation as a link between obesity, metabolic syndrome and type 2 diabetes. Diabetes Res Clin Pract. 2014;105(2):141-150. doi:10.1016/j.diabres.2014.04.006

12. Hamilton MT, Hamilton DG, Zderic TW. The role of low energy expenditure and sitting on obesity, metabolic syndrome, type 2 diabetes, and cardiovascular disease. Diabetes. 2007;56:2655-2667. doi: $10.2337 / \mathrm{db} 07-0882$

13. Chatterjee S, Khunti K, Davies MJ. Type 2 diabetes. Lancet. 2017;389(10085):2239-2251. doi:10.1016/S0140-6736(17)30058-2

14. Nahas R, Moher M. Complementary and alternative medicine for the treatment of type 2 diabetes. Can Fam Physician. 2009;55(6):591-596.

15. Pahlavani N, Roudi F, Zakerian M, et al. Possible molecular mechanisms of glucose-lowering activities of Momordica charantia (karela) in diabetes. J Cell Biochem. 2019;120:10921-10929. doi:10.1002/ jcb.v120.7

16. Hosseinzadeh H. Saffron: a herbal medicine of third millennium. Jundishapur J Nat Pharm Prod. 2014;9(1):1-2.

17. Alavizadeh SH, Hosseinzadeh H. Bioactivity assessment and toxicity of crocin: a comprehensive review. Food Chem Toxicol. 2014;64:6580. doi:10.1016/j.fct.2013.11.016

18. Mohamadpour AH, Ayati Z, Parizadeh MR, Rajbai O, Hosseinzadeh H. Safety evaluation of crocin (a constituent of saffron) tablets in healthy volunteers. Iran J Basic Med Sci. 2013;16(1):39.

19. Azimi P, Ghiasvand R, Feizi A, Hariri M, Abbasi B. Effects of cinnamon, cardamom, saffron, and ginger consumption on markers of glycemic control, lipid profile, oxidative stress, and inflammation in type 2 diabetes patients. Rev Diabet Stud. 2014;11(3-4):258-266. doi:10.1900/RDS.2014.11.258

20. Milajerdi A, Jazayeri S, Hashemzadeh N, et al. The effect of saffron (Crocus sativus L.) hydroalcoholic extract on metabolic control in type 2 diabetes mellitus: a triple-blinded randomized clinical trial. $J$ Res Med Sci. 2018;23:16.

21. Suresh K, Chandrashekara S. Sample size estimation and power analysis for clinical research studies. J Hum Reprod Sci. 2012;5 (1):7. doi:10.4103/0974-1208.97779

22. Vasheghani-Farahani A, Tahmasbi M, Asheri H, Ashraf H, Nedjat S, Kordi R. The Persian, last 7-day, long form of the international physical activity questionnaire: translation and validation study. Asian J Sports Med. 2011;2(2):106. doi:10.5812/asjsm

23. Pahlavani N, Entezari M, Nasiri M, et al. The effect of 1-arginine supplementation on body composition and performance in male athletes: a double-blinded randomized clinical trial. Eur J Clin Nutr. 2017;71(4):544. doi:10.1038/ejen.2016.266

24. Ghaffarpour M, Houshiar-Rad A, Kianfar H. The Manual for Household Measures, Cooking Yields Factors and Edible Portion of Foods. Vol. 7. Tehran: Nashre Olume Keshavarzy; 1999:213. 
25. Mohammadifard N, Sajjadi F, Maghroun M, Alikhasi H, Nilforoushzadeh F, Sarrafzadegan N. Validation of a simplified food frequency questionnaire for the assessment of dietary habits in Iranian adults: Isfahan Healthy Heart Program, Iran. ARYA Atheroscler. 2015;11(2):139.

26. Miller NJ, Rice-Evans C, Davies MJ, Gopinathan V, Milner A. A novel method for measuring antioxidant capacity and its application to monitoring the antioxidant status in premature neonates. Clin Sci. 1993;84(4):407-412. doi:10.1042/cs0840407

27. Richard MJ, Portal B, Meo J, Coudray C, Hadjian A, Favier A. Malondialdehyde kit evaluated for determining plasma and lipoprotein fractions that react with thiobarbituric acid. Clin Chem. 1992;38 (5):704-709.

28. Bodmer M, Meier C, Krähenbühl S, Jick SS, Meier CR. Metformin, sulfonylureas or other antidiabetic drugs and the risk of lactic acidosis or hypoglycemia: a nested case-control analysis. Diabetes Care. 2008;31:2086-2091. doi:10.2337/dc08-1171

29. Leone S, Recinella L, Chiavaroli A, et al. Phytotherapic use of the Crocus sativus L. (Saffron) and its potential applications: a brief overview. Phytother Res. 2018;32:2364-2375. PubMed PMID: 30136324. Epub 2018/ 08/24.eng. doi:10.1002/ptr.v32.12

30. Khatir SA, Bayatian A, Barzegari A, Roshanravan N, Safaiyan A, Pavon-Djavid G, et al. Saffron (Crocus sativus L.) Supplements Modulate Circulating MicroRNA (miR-21) in Atherosclerosis Patients; A Randomized, Double-Blind, Placebo-Controlled Trial. Iranian Red Crescent Medical Journal. 2018;20(10).

31. Mohammadierad R, Mohammad-Alizadeh-Charandabi S, Mirghafourvand M, Fazil F.Effect of Saffron with or Without Date Sugar on Intensity of Pain and Anxiety During Labor in Primiparous Females: a Randomized, Controlled Trial. Iran Red Crescent Med J. 2018;20(S1):e61289.

32. Vijaya Durga P, Kumaraswamy B, Dhanaraju M, Ramachandran S. Antihyperglycemic, hypolipidemic and antioxident effect of aqueous extract of coriander sativum (seed) and ginger officinale (rhizome) combination in streptozotocin induced diabetes mellitus rats. Int $J$ Biol Pharm Res. 2013;4(12):872-877.
33. Sahraian A, Jelodar S, Javid Z, Mowla A, Ahmadzadeh L. Study the effects of saffron on depression and lipid profiles: a double blind comparative study. Asian J Psychiatr. 2016;22:174-176. doi:10.1016/ j.ajp.2015.10.012

34. Bandara T, Uluwaduge I, Jansz ER. Bioactivity of cinnamon with special emphasis on diabetes mellitus: a review. Int J Food Sci Nutr. 2012;63(3):380-386. doi:10.3109/09637486.2011.627849

35. Shirali S, Zahra Bathaie S, Nakhjavani M. Effect of crocin on the insulin resistance and lipid profile of streptozotocin-induced diabetic rats. Phytother Res. 2013;27(7):1042-1047. doi:10.1002/ptr.4836

36. HAZMAN Ö, Aksoy L, BÜYÜKBEN A. Effects of crocin on experimental obesity and type-2 diabetes. Turk J Med Sci. 2016;46 (5):1593-1602. doi:10.3906/sag-1506-108

37. Hosseinzadeh H, Younesi HM. Antinociceptive and anti-inflammatory effects of Crocus sativus L. stigma and petal extracts in mice. BMC Pharmacol. 2002;2:7. doi:10.1186/1471-2210-2-7

38. Xiang M, Qian ZY, Zhou CH, Liu J, Li WN. Crocetin inhibits leukocyte adherence to vascular endothelial cells induced by AGEs. $J$ Ethnopharmacol. 2006;107(1):25-31. doi:10.1016/j.jep.2006.01.022

39. Naghshineh A, Dadras A, Ghalandari B, et al. Safranal as a novel anti-tubulin binding agent with potential use in cancer therapy: an in vitro study. Chem Biol Interact. 2015;238:151-160. doi:10.1016/j. cbi.2015.06.023

40. Milajerdi A, Djafarian K, Hosseini B. The toxicity of saffron (Crocus sativus L.) and its constituents against normal and cancer cells. J Nutr Intermed Metab. 2016;3:23-32. doi:10.1016/j.jnim.2015.12.332

41. Talebnejad MR, SOlTanzadeh K, Masoomeh E, Yasemi M, Khalili MR, Maryam S. Effect of intraperitoneal injection of saffron on the treatment of experimental endotoxin induced uveitis in the rabbit. $J$ Clin Diagn Res. 2017;11(3):NC01. doi:10.7860/JCDR/2017/24731. 9963

42. Pourmasoumi M, Hadi A, Najafgholizadeh A, Kafeshani M, Sahebkar A. Clinical evidence on the effects of saffron (Crocus sativus L.) on cardiovascular risk factors: a systematic review meta-analysis. Pharmacol Res. 2018;139:348-359. doi:10.1016/j.phrs.2018.11. 038

Diabetes, Metabolic Syndrome and Obesity: Targets and Therapy

Dovepress

\section{Publish your work in this journal}

Diabetes, Metabolic Syndrome and Obesity: Targets and Therapy is an international, peer-reviewed open-access journal committed to the rapid publication of the latest laboratory and clinical findings in the fields of diabetes, metabolic syndrome and obesity research. Original research, review, case reports, hypothesis formation, expert opinion and commentaries are all considered for publication. The manuscript management system is completely online and includes a very quick and fair peer-review system, which is all easy to use. Visit http://www.dovepress.com/testimonials.php to read real quotes from published authors. 